$16^{\text {th }}$ International Congress of Metrology, 05003 (2013)

DOI: $10.1051 /$ metrology/201305003

(C) Owned by the authors, published by EDP Sciences, 2013

\title{
Conformity assessment of a high-performance liquid chromatography calibration.
}

\author{
Ginett Vargas Hoyos ${ }^{1}$ and Gilberto González Horta ${ }^{2}$ \\ ${ }^{1}$ Center of Molecular Immunology, Engineering Management, Metrology Department, 216 esq 15 Atabey Havana, Cuba \\ ${ }^{2}$ Center of Molecular Immunology, Quality Management, Validation Department, 216 esq 15 Atabey Havana, Cuba
}

\begin{abstract}
This evaluation presents the results obtained in the study of the qualification protocol of the High Performance Liquid Chromatography (HPLC) in the Center of Molecular Immunology. As a criterion for the Conformity Assessment Calibration of different measurement channels, it is proposed to obtain a Probability of Calibration Conformance greater than or equal to $95 \%$ in concordance with existing regulations for the biopharmaceutical industry. This can be achieved by calculating the measurement capability, an index closely related to the evaluation of the uncertainty of the measured parameter and tolerance of process involving this measurement, which determines the range of acceptable fit for the measurement channel in accordance with the probability of the desired calibration line.
\end{abstract}

\section{Introduction}

The Center of Molecular Immunology (CIM) is a biotechnological institution dedicated to the research, development, production, and marketing of monoclonal antibodies, recombinant proteins and vaccines, in accordance with the requirements of current Good Manufacturing Practices (cGMP) and the standards set by national and international regulatory agencies. Its main objective is to achieve therapeutic products with high levels of safety and effectiveness mainly aimed at patients suffering from non-transmissible chronic diseases.

In the CIM, performance measurements acquire a significant level. In addition to being one of the main sources of information about technical parameters, characteristics, and efficiencies of technological processes, the measurements also certify the quality of execution of all activity productions, which defines whether the product complies with all the established parameters and prevents the output of low quality products to the consumer.

Obtaining a reliable measurement result is only possible if you take into consideration the elements that constitute the technical basis for establishing confidence in the measurement. One of these elements is the assessment of uncertainty, a property closely related to the concepts of traceability, accuracy, error, and tolerance.

Uncertainty in measurements may lead to acceptance of certain amount of products out of tolerance or rejection of others within the range of tolerance; this can result in mistaken acceptance or rejection of products.

This is also true for calibration; for instance, if the conformity assessment of the measurement device calibration is supported by a measurement with limited conformity, the error acquires two nuances: the acceptance of an inadequate instrument or the dismissal of a satisfactory measuring instrument.

New concepts have been introduced, such as Measurement Capability and Conformance Probability [1] which are effective tools on determining the conformity of the performed calibration.

Within the critical equipment involved in process control and quality control in the CIM are the High 
Resolution Liquid Chromatographs, which are commonly called HPLC. In accordance with the compliance of cGMP and cGLP (current Good Laboratory Practice) such equipment regularly undergoes qualification processes, where the calibration of all measuring channels is required for the evaluation and qualification of the operation and subsequently their performance.

The main objective of this report is to examine in depth the operational qualification protocol developed by the manufacturer of HPLC to evaluate the metrological characteristics of this equipment and determine the adequacy of the measurement systems used to calibrate them. Uncertainty sources are characterized for each measurement channel and their results are evaluated.

The measurement capability was calculated from the uncertainty values obtained and the acceptance interval was defined to achieve a Probability of Calibration Conformity greater than or equal to $95 \%$. In necessary cases, recommendations will be made to improve operational protocol qualification or corresponding changes will be proposed for the measurement channels of the equipment. The study examined three different models of HPLC: Model I, Model II, Model III.

\section{METHOD AND ANALYSIS}

CIM has HPLC equipments of different manufactures in their quality control departments and process control laboratories, which are used in process control and to perform quantitative analysis of the evaluated samples of finished products. Figure 1 shows a simplified diagram of a HPCL.

Figure 1. Diagram of the main components of a High- Performance Liquid Chromatograph.

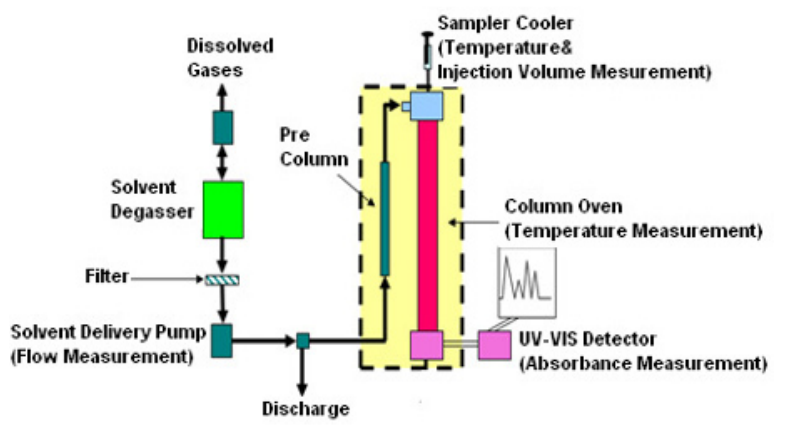

Table 1 shows the characteristics that the manufacturer gives for each model. Only shows those used in the study.

Table 1. Technical specifications for each model [2].

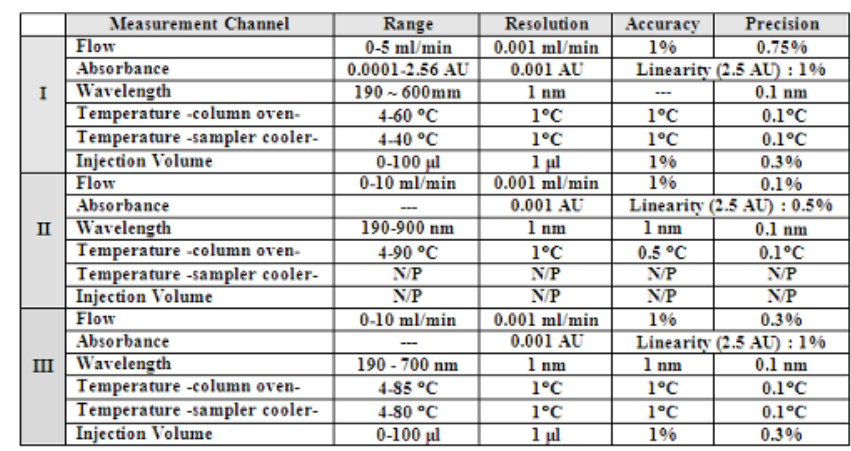

The proper calibration of the HPLC measurement systems is essential to ensure the traceability of measurements performed in this equipment.

Conformity assessment is any activity to determine, directly or indirectly, that a process, product, or system meets relevant technical standards or requirements. [1]

In this particular case, this study evaluates the conformity of the calibration, which will determine whether measuring instrument is within appropriate limits for use.

The correct definition of the interval of permissible values for a calibration (acceptance interval), allows to equilibrate the risk of error in taking the decision of acceptance or rejection associated with the uncertainty of the calibration. In this work is recommended to address the problem of conformity assessment of calibration using the concepts of Probability Density Function of the measurement, Tolerance Interval -on a measuring instrument is the maximum permissible error (Emáx)- and acceptance interval limits - on a calibration is acceptance of it -

Figure 2 shows the relationship between the Tolerance Interval [Emáx] and Calibration Acceptance Interval. The resulting value of a measurement during calibration shall be within the Tolerance Interval $\left[-\mathrm{E}_{\text {máx; }}\right.$ $\left.E_{\text {máx }}\right]$. The measurement will be conform if the value being within the Acceptance Interval defined by $A_{L}$ and $\mathrm{A}_{\mathrm{U}}$.

Figure 2. Tolerance Interval and Calibration Acceptance Interval related to the conformity assessment of the calibration. 


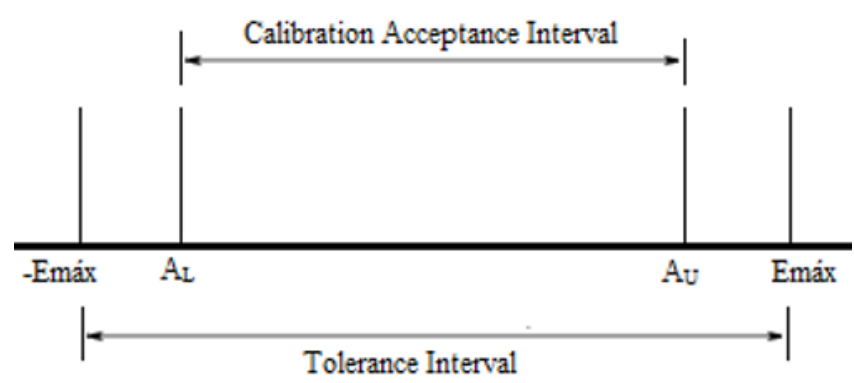

The maximum permissible error is given by the manufacturer and the definition of acceptance limits of the calibration will depend on the required measurement quality.

The result of measuring a magnitude $\mathbf{Y}$ that is expressed as $\boldsymbol{y}$, is obtained by estimating the measured value and the parameter which characterizes the dispersion values can be reasonably assigned to that, that is, the measurement uncertainty $\left[\boldsymbol{u}_{\boldsymbol{m}}\right]$. The Probability Density Function of a measurement $\boldsymbol{\eta} \boldsymbol{m}$ characterizes the possible values that can take it.

The $\mathrm{Cm}$ Measurement Capacity is defined in [1] as:

$$
C m=T / 4 u_{m}
$$

The interval $\left[\mathrm{y}-2 \boldsymbol{u}_{\boldsymbol{m}} ; \mathrm{y}+2 \boldsymbol{u}_{\boldsymbol{m}}\right]$ must contain a significant portion $(\approx 95 \%)$ of the distribution of values that could reasonably be attributed to $\mathrm{Y}$.

In the calibration of a measurement instrument, a specified requirement is often expressed in terms of a maximum permissible error $\mathrm{E}[$ máx $]$, that is, the indication error must be in the interval $\left[-\mathrm{E}_{\text {máx; }} \mathrm{E}_{\text {máx }}\right]$ Tolerance is therefore $\quad \mathrm{T}=2 \mathrm{E}_{\text {máx }}$ and Measurement Capability would like:

$$
C m=2 E \max / 2 U=\operatorname{Emax} / U
$$

En la calibración de un instrumento de medición un requisito usualmente utilizado se expresa como el error máximo permisible $\left[\mathrm{E}_{\text {máx }}\right]$, o sea, que el error de indicación debe encontrarse en el intervalo $\left[-\mathrm{E}_{\text {máx; }} \mathrm{E}_{\text {máx }}\right]$. Por tanto la tolerancia es $\mathrm{T}=2 \mathrm{E}_{\text {máx }}$ y la capacidad de medición quedaría como:

This index is closely linked with the term Probability of Conformity that characterizes the probability that a measurement meets the specified requirements. Conformance Probability can be expressed in terms of Tolerance Intervals $\mathrm{T}_{\mathrm{L}}$ y $\mathrm{T}_{\mathrm{U}}$ (lower and upper) and the particular measurement result expressed as (y, u), which in this case would be $\mathrm{y} \approx \eta_{\mathrm{m}}$ and $\mathrm{u} \approx \mathrm{u}_{\mathrm{m}}$.
From here is defined in [1] a new term $\tilde{y}$ that characterizes the proximity of the measurement at the tolerance limits of it:

$$
\tilde{y}=\left(\eta_{m}-T_{L}\right) / T
$$

For a measured value $\eta \mathrm{m}$ in the tolerance interval, $\tilde{\boldsymbol{y}}$ is in the range $0 \leq \tilde{\boldsymbol{y}} \leq 1$.

Finally, all these elements are related by the curve of constant $95 \%$ conformance probability [1]. This curve separates the areas of conformity of non-conformity with $95 \%$ of confidence.

Figure 3. Curve of constant $95 \%$ conformance probability.

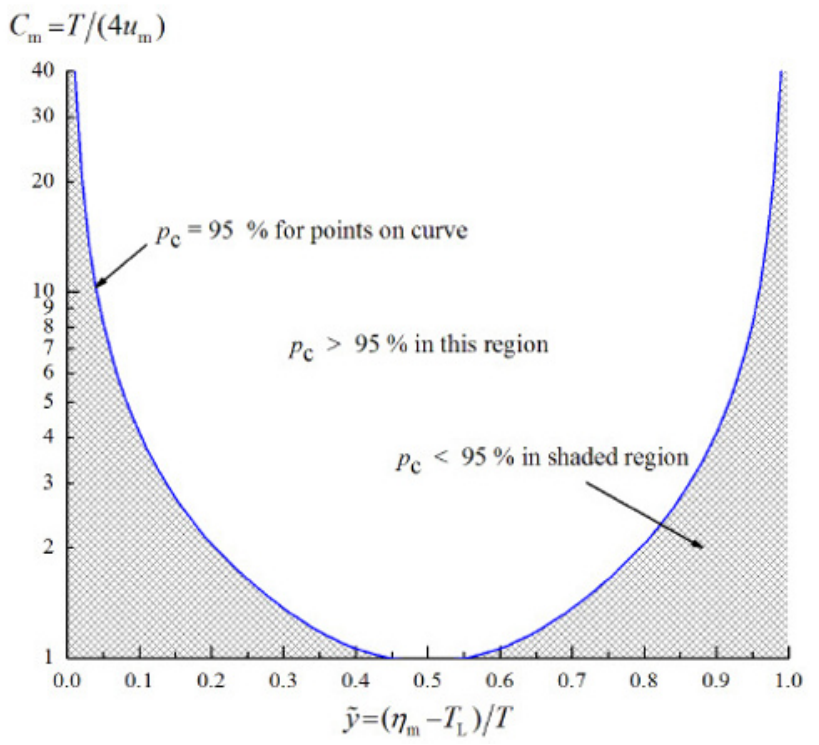

In the decision to accept or not the measurement (calibration) is involved the value of the estimated uncertainty, that directly affects the value of $\mathrm{Cm}$. It may be noted that the lower this value the narrower the interval to get a Conformance Probability greater or equal to $95 \%$.

\subsection{Results}

For good performance, the HPLC has the following measurement channels:

- Flow (Pump Solvent Delivery)

- Absorbance (UV-VIS-Detector)

- Column Oven Temperature

- Sample Cooler Temperature (Sampler Cooler)

- Injection Volume.

For each model was evaluated the calibration uncertainty according to GUM [31, following the procedure established by the manufacturer. 
From the calculated uncertainty in the calibration of each measurement channel of the HPLC, it proceeded to calculate the measurement capability and define the acceptance interval for the conformity assessment of the calibration. The values obtained for each model studied are shown in Tables 2, 3 and 4.

Tolerance intervals are those established by the manufacturer's protocol qualification.

The expanded uncertainty -Uexp- is calculated for a confidence level of $95 \%(\mathrm{k}=2)$, from the evaluation of the combined uncertainty of each measurement channel. It should be noted that the main contribution to the uncertainty of the calibration is provided by the measurement channels of the HPLC.

Table 2. Measurement capability and calibration acceptance intervals of model i for a conformance probability greater than or equal to $95 \%$.

\begin{tabular}{|c|c|c|c|c|}
\hline \multicolumn{5}{|c|}{ MODEL I } \\
\hline Magnitude & \begin{tabular}{|l|} 
Toleranec Interval \\
\end{tabular} & Uexp & $\begin{array}{l}\text { Measurement } \\
\text { Capability }\end{array}$ & Acecptanee Interval ${ }^{\circ}$ \\
\hline $\begin{array}{l}\text { Flow Accuracy } \\
-1 \mathrm{ml} / \mathrm{min}-\end{array}$ & $\begin{array}{c} \pm 2 \% \\
(0.02 \mathrm{ml} / \mathrm{min}) \\
(0.98-1.02 \mathrm{~mL} / \mathrm{mmin})\end{array}$ & $0.0115 \mathrm{ml} / \mathrm{min}$ & 1.73 & $\begin{array}{c}25-75 \% \\
(0.985-1.015 \mathrm{ml} / \mathrm{min})\end{array}$ \\
\hline $\begin{array}{l}\text { Absorbance } \\
\text { Aceuracy } \\
-0.514 \mathrm{AU} \text {. }\end{array}$ & $\begin{array}{c} \pm 5 \% \\
(0.0257 \mathrm{AU}) \\
(0.4883-0.5397 \mathrm{AU})\end{array}$ & $0.0102 \mathrm{AU}$ & 2.52 & $\begin{array}{c}16-84 \% \\
(0.4924-0.5356 \mathrm{AU})\end{array}$ \\
\hline $\begin{array}{l}\text { Absorbance } \\
\text { Accuracy } \\
-2.5917 \mathrm{AU} \text {. }\end{array}$ & $\begin{array}{c} \pm 5 \% \\
(0.1296 \mathrm{AU}) \\
(2.4621-2.7213 \mathrm{AU})\end{array}$ & $0.0426 \mathrm{AU}$ & 3.04 & $\begin{array}{c}14-86 \% \\
(2.4802 \cdot 2.7032 . A U)\end{array}$ \\
\hline $\begin{array}{l}\text { Oven } \\
\text { Temperature } \\
.40^{\circ} \mathrm{C}-\end{array}$ & $\begin{array}{c} \pm 2^{\circ} \mathrm{C} \\
\left(38.42^{\circ} \mathrm{C}\right)\end{array}$ & $1.392^{\circ} \mathrm{C}$ & 1.44 & $\begin{array}{c}30-70 \% \\
\left(38.6-41.4^{\circ} \mathrm{C}\right)\end{array}$ \\
\hline $\begin{array}{c}\text { Samplor Cooler } \\
\text { Temperature } \\
-4^{\circ} \mathrm{C} \text { - }\end{array}$ & $\begin{array}{l} \pm 3^{\circ} \mathrm{C} \\
\left(1-7^{\circ} \mathrm{C}\right)\end{array}$ & $1.375^{\circ} \mathrm{C}$ & 2.18 & $\begin{array}{c}20-80 \% \\
\left(1.6-6.4{ }^{\circ} \mathrm{C}\right)\end{array}$ \\
\hline $\begin{array}{c}\text { Injection Volume } \\
-50 \mu 1-\end{array}$ & $\begin{array}{c} \pm 2 \% \\
(1) \mu \nu \\
\left(49.51 \mu \mu^{2}\right)\end{array}$ & $0.9776 \mu \mathrm{ll}$ & 1.00 & $\begin{array}{c}45-55 \% \\
(49,45-50.55 \mu 1)\end{array}$ \\
\hline
\end{tabular}

* Acceptance intervals are given in \% of the Tolerance Intervals.

Table 3. Measurement capability and calibration acceptance intervals of model ii for a conformance probability greater than or equal to $95 \%$.

\begin{tabular}{|c|c|c|c|c|}
\hline \multicolumn{5}{|c|}{ MODEL II } \\
\hline Magnitude & Tolerance Interval & Vexp & $\begin{array}{l}\text { Messurement } \\
\text { Capability }\end{array}$ & Acceptance Interval" \\
\hline $\begin{array}{l}\text { Flow Accuracy } \\
-1 \mathrm{ml} / \mathrm{min} \text { - }\end{array}$ & $\begin{array}{c} \pm 2 \% \\
(0.02 \mathrm{~mL} / \mathrm{min}) \\
(0.98-1.02 \mathrm{~mL} / \mathrm{min})\end{array}$ & $0.0116 \mathrm{ml} / \mathrm{min}$ & 1.73 & $\begin{array}{c}25-75 \% \\
(0.985-1.015 \mathrm{ml} / \mathrm{min})\end{array}$ \\
\hline $\begin{array}{l}\text { Absorbance } \\
\text { Accuracy } \\
-0.514 \mathrm{AU} \text {. }\end{array}$ & $\begin{array}{c} \pm 5 \% \\
(0.0257 \mathrm{AU}) \\
(0.4883-0.5397 \mathrm{AU})\end{array}$ & $0.0087 \mathrm{AU}$ & 2.95 & $\begin{array}{c}15-85 \% \\
(0.4922-0.5358 \text { AU) }\end{array}$ \\
\hline $\begin{array}{l}\text { Absorbance } \\
\text { Accuracy } \\
-2.5917 \mathrm{AU} \text {. }\end{array}$ & $\begin{array}{c} \pm 5 \% \\
(0.1296 \mathrm{AU}) \\
(2.4621-2.7213 \mathrm{AU})\end{array}$ & $0.0339 \mathrm{AU}$ & 3.82 & $\begin{array}{c}12-88 \% \\
(2.4776-2.7057 \text { AU) }\end{array}$ \\
\hline $\begin{array}{l}\text { Oven } \\
\text { Temperature } \\
-40^{\circ} \mathrm{C} \text {. }\end{array}$ & $\begin{array}{c} \pm 2{ }^{\circ} \mathrm{C} \\
\left(38^{\circ}-42^{\circ} \mathrm{C}\right)\end{array}$ & $0.973 \mathrm{C}$ & 2.06 & $\begin{array}{c}20-80 \% \\
\left(38.4-41.6^{\circ} \mathrm{C}\right)\end{array}$ \\
\hline
\end{tabular}

* Acceptance intervals are given in \% of the tolerance intervals.

Table 4. Measurement capability and calibration acceptance intervals of model iii for a conformance probability greater than or equal to $95 \%$.

\begin{tabular}{|c|c|c|c|c|}
\hline \multicolumn{5}{|c|}{ MODEL III } \\
\hline Magnitude & Tolerance Interval & Uexp & $\begin{array}{l}\text { Measurement } \\
\text { Capability }\end{array}$ & Aeeeptanee Interval ${ }^{x}$ \\
\hline $\begin{array}{l}\text { Flow Accuracy } \\
-1 \mathrm{ml} / \mathrm{min-}\end{array}$ & $\begin{array}{c} \pm 2 \% \\
(0.02 \mathrm{ml} / \mathrm{min}) \\
(0.93-1.02 \mathrm{ml} / \mathrm{min})\end{array}$ & $0.0116 \mathrm{ml} / \mathrm{min}$ & 1.73 & $\begin{array}{c}25-75 \% \\
(0.985-1.015 \mathrm{~m} / \mathrm{min})\end{array}$ \\
\hline $\begin{array}{l}\text { Absorbance } \\
\text { Accuracy } \\
-0.514 \mathrm{AU} \text {. }\end{array}$ & $\begin{array}{c} \pm 3 \% \\
(0.0257 \mathrm{AU}) \\
(0.4883 .0 .5397 \mathrm{AL})\end{array}$ & $0.0102 \mathrm{AU}$ & 2.52 & $\begin{array}{c}16-84 \% \\
(0.4924-0.5356 \mathrm{AU})\end{array}$ \\
\hline $\begin{array}{c}\text { Absorbance } \\
\text { Accuracy } \\
-2.5917 \mathrm{AU} \text {. }\end{array}$ & $\begin{array}{c}\mathbf{\pm 3} \% \\
(0.1296 \mathrm{AU}) \\
(2.4621-2.7213 \mathrm{AC})\end{array}$ & $0.0426 \mathrm{AU}$ & 3.04 & $\begin{array}{c}14-86 \% \\
(2,4802 \cdot 2.7032 \text { AU) }\end{array}$ \\
\hline $\begin{array}{l}\text { Oven } \\
\text { Temperature } \\
40^{\circ} \mathrm{c} \text {. }\end{array}$ & $\begin{array}{c} \pm 2^{\circ} \mathrm{C} \\
\left(38^{\circ}-42^{\circ} \mathrm{C}\right)\end{array}$ & $1.3922^{\circ} \mathrm{C}$ & 1.44 & $\begin{array}{c}30-70 \% \\
\left(38.6-41.4^{\circ} \mathrm{C}\right)\end{array}$ \\
\hline $\begin{array}{c}\text { Sampler Cooler } \\
\text { Temperature } \\
4^{\circ} \mathrm{C} \text {. }\end{array}$ & $\begin{array}{c} \pm 3{ }^{\circ} \mathrm{C} \\
\left(1-7^{\circ} \mathrm{C}\right)\end{array}$ & $1.375^{\circ} \mathrm{C}$ & 2.18 & $\begin{array}{c}20-80 \% \\
\left(1.6-6.4^{\circ} \mathrm{C}\right)\end{array}$ \\
\hline $\begin{array}{c}\text { Injection Volume } \\
-50 \mathrm{pl}-\end{array}$ & $\begin{array}{l} \pm 2 \% \\
(1, \mu) \\
(49-51 \mu 1)\end{array}$ & $0.9776 \mu \mathrm{l}$ & 1.00 & $\begin{array}{c}45-55 \% \\
(49,45-50.55 \mu)\end{array}$ \\
\hline
\end{tabular}

* Acceptance intervals are given in $\%$ of the tolerance intervals.

\subsection{Discussion}

From the calculations obtained can be made the following observations:

- The assessment of the calibration uncertainty of the flow channel was performed by the type $\mathrm{A}$ in model I and by the type B in the rest of them. In each case similar results were obtained, despite the repeatability given by the manufacturer for the model I is greater than in other models. This induces to increasing the number of observations and evaluating uncertainty type A reduces its value, but doing it the cost of the calibration increases. Regardless of the precision data from models II and III are lower than the model I, the contribution to the uncertainty is of the same order because only one observation was made. Measurement capability obtained for the flow channel warn the need to make modifications, either by increasing the number of observations to improve the assessment of uncertainty by repeatability or improving the accuracy of measurement channel of a HPLC.

- Calibration of absorbance channel is made on extreme values of the linearity test of the absorbance of qualification protocol. The linearity data given by the manufacturer is critical in the measurement capability values obtained.

- Calibration of the temperature measurement channels of the oven and sampler cooler is acceptable, although in the case of temperature channel of the oven the acceptance interval is slightly smaller due to the influence of the measurement temperature accuracy of HPLC. Also, this is demonstrated by observing the increase in measurement capability in the temperature channel of the oven of model II, as it has a better accuracy.

- The acceptance interval obtained for a Conformance Probability of $95 \%$ in the injection 
volumen for models I and II is minimal. In this case, the low measurement capability is directly associated with the measurement channel accuracy, but more than anything with the measurement procedure; that indicates to take only one observation. If this procedure change, for example, increasing the number of observations, it would improve the assessment of uncertainty, in addition, increase the measurement capability to achieve a wider acceptance interval. Certainly, this leads to an increase in calibration time and expenses

\section{Conclusions}

It was studied in depth the protocol operation qualification of HPLC, it was assessed the calibration uncertainty of each measurement channel and determined the interval to achieve a conformance probability of the calibration greater than or equal to $95 \%$.

It was found that in all cases the main contribution to the calibration uncertainty is given by the metrological characteristics of the measuring channels of the HPLC, which directly affects the measurement capability obtained for each measurement channel in each model studied.

From the results we propose the following recommendations:
- Valuate the number of observations to be made in the calibration of flow measurement channels and injection volume to improve the uncertainty assessments that provide the accuracy and repeatability of these. There must be a cost-benefit analysis for the possible increase in the number of observations.

- $\quad$ Achieve very precise adjustment of the temperature measurement channels, particularly the oven temperature to ensure measurement locate within the acceptance intervals.

\section{References}

[1] Joint Committee for Guides in Metrology; "Evaluation of measurement data. The role of measurement uncertainty in conformity assessment”. JCGM 106: 2012.

[2] Manufacturer Reference Manual; 2010.

[3] Joint Committee for Guides in Metrology; "Evaluation of measurement data - Guide to the expression of uncertainty in measurement" .JCGM 100: 2008.

[4] Joint Committee for Guides in Metrology; “ International Vocabulary of Metrology - Basic and general concepts and associated terms (VIM)". JCGM 200: 2008. 